\title{
Measuring Ad-Evoked Nostalgia in India: An Emerging Market Perspective-An Abstract
}

\author{
Varsha Jain, Altaf Merchant, Subhadip Roy, and John B. Ford
}

\begin{abstract}
In the current inquiry we add to evolving research on how consumers respond to nostalgic advertising by examining the cultural differences in the evocation of nostalgia. We contend that nostalgic reverie can engage the consumer, but there are cultural differences in the types of nostalgia that are evoked among consumers. We discuss work-in-progress findings from three studies in India that reveal that ad-evoked nostalgia has five dimensions: personal memories, positive emotions, negative emotions, physiological reactions, and collective nostalgia. These findings are unique and distinct from previous research. In this present research involving India, there is concurrent evocation of individual and collective dimensions of nostalgia. These findings are novel and useful from a theoretical and managerial perspective and should be viewed in the backdrop of a large emerging middle class in India and the predominant collective nature of the country.
\end{abstract}

References available upon request.

V. Jain $(\bowtie)$

Mudra Institute of Communications, Ahmedabad, Gujarat, India

e-mail: varsha@micamail.in

A. Merchant

University of Washington, Seattle, WA, USA

e-mail: altafm@uw.edu

S. Roy

Indian Institute of Management, Udaipur, Rajasthan, India

e-mail: subhadip.roy@iimu.ac.in

J.B. Ford

Old Dominion University, Norfolk, VA, USA

e-mail: jbford@odu.edu 